\title{
POSSÍVEIS CONTRIBUIÇÕES DE UM TRABALHO COM NARRATIVAS DE VIDA PARA O DESENVOLVIMENTO PESSOAL E PROFISSIONAL DE ALUNOS DO ENSINO MÉDIO-TÉCNICO PROFISSIONALIZANTE ${ }^{1}$
}

\author{
Ana Paula Marques BEATO-CANATO \\ (Universidade Federal do Rio de Janeiro) \\ anabeato@uol.com.br
}

\begin{abstract}
Resumo: Atualmente, o ensino-aprendizagem de línguas para fins específicos tem sido focado em gêneros textuais e temas avaliados como relevantes para o meio profissional e/ou acadêmico no qual os estudantes possivelmente atuarão (RAMOS, 2004; BEATO-CANATO, 2011). Todavia, no ensino de nível médiotécnico profissionalizante, a disciplina engloba objetivos mais amplos referentes ao desenvolvimento dos aprendizes como cidadãos. A intenção deste texto é relatar um trabalho realizado que buscou abranger a formação profissional e pessoal de adolescentes, ao contemplar documentários sobre o tema da unidade - $A$ história da Química -, biografias de cientistas famosos, narrativas de vida, entrevistas com docentes e funcionários e produção de vídeos. É factível assegurar que $o$ trabalho favoreceu o desenvolvimento individual e coletivo pessoal e profissional dos participantes.
\end{abstract}

Palavras-chave: Ensino médio-técnico profissionalizante. Língua estrangeira para fins específicos. História da química. Desenvolvimento pessoal e profissional. Narrativas de vida

Abstract: Currently, the language learning-teaching process for specific purposes is focused on genres and themes evaluated as relevant in the academic and professional field where students will probably work. Although, in a high school context which aims at contributing to the academic and professional education of students, the subject involves more general objectives concerning the development of students as citizens. This text aims at reporting the results of a work which, considering its context, attempted to comprise the professional and personal development of the adolescents, covering documentaries about the theme of the unit - Chemistry history -, biographies of famous scientists, life narrative, teachers and employees interviews and video production. It is possible to assert that the work favored the individual and collective development, personally and professionally.

Keywords: Technical and vocational high school. Foreign language for specific purposes. Chemistry history. Personal and professional development. Narratives.

\footnotetext{
${ }^{1}$ Este trabalho foi apresentado oralmente, como comunicação individual, durante o IX CBLA, ocorrido em julho de 2011, na Universidade Federal do Rio de Janeiro (UFRJ).
} 


\section{Introdução}

Cursos/disciplinas de línguas para fins específicos no contexto de ensinoaprendizagem de nível médio-técnico profissionalizante englobam objetivos profissionais e referentes ao desenvolvimento dos aprendizes como cidadãos, como orientam os documentos oficiais (BRASIL, 2007) que preconfiguram tal âmbito educacional.

Em uma visão vigotskiana, desenvolvimento é entendido como

um complexo processo dialético, caracterizado pela periodicidade, irregularidade no desenvolvimento das diferentes funções, metamorfose ou transformação qualitativa de uma forma em outra, entrelaçamento de fatores externos e internos e processos adaptativos (VIGOTSKI, 2007, p.138)

Nessa ótica, a atividade didático-pedagógica pode ser compreendida como uma empreitada multifacetada, que precisa respeitar a complexidade e a delonga do processo, bem como atender às expectativas dos alunos, considerar as preconfigurações oficiais macro e micro, contemplar as necessidades percebidas em um contexto macro.

Partindo dessas premissas, o trabalho descrito neste texto foi realizado em 2010, em uma instituição federal de nível médio-técnico profissionalizante, em turmas de quinto período de Química, Farmácia e Biotecnologia, na disciplina de Inglês para Fins Específicos 1, cujo conteúdo programático, na época, era dividido em temas e estratégias.

Com o objetivo de favorecer o desenvolvimento dos participantes para agir profissional e academicamente, ao mesmo tempo que pudessem ampliar o conhecimento de si, na unidade com o tema história da química, foram focalizados os seguintes gêneros: documentário sobre o tema da unidade, biografias de cientistas da área e histórias de vida pessoais, vistas como uma maneira de educar a si mesmo (VASCONCELOS; CARDOSO, 2009, p.654).

O envolvimento dos aprendizes foi expressivo e, em conjunto, optamos por ampliar o escopo com o intuito de conhecer um pouco da vida dos docentes e de funcionários da instituição. Nesta etapa, entrevistas com alguns 
profissionais foram realizadas e seus resultados organizados em apresentações para a turma e convidados (professores e funcionário). Como muitos produziram vídeos, coletivamente optamos por organizá-los em um DVD, entregue a professores e funcionários que participaram do projeto.

É plausível assegurar que o trabalho realizado configurou-se como holístico, possibilitando o desenvolvimento individual e coletivo, pessoal e profissional dos participantes, na medida em que as atividades favoreceram a construção de conhecimento a respeito de si, do grupo e da instituição como um todo, além de viabilizar o desenvolvimento de capacidades de linguagem.

\section{Alguns pressupostos}

A unidade partiu do princípio de que "todos os diversos campos da atividade humana estão ligados ao uso da linguagem (BAKHTIN, 2010, p.261)", que é um instrumento semiótico construído socialmente, fundador e organizador de todos os processos psicológicos em suas dimensões especificamente humanas, tais como percepção, cognição, sentimentos e emoções (BRONCKART, 2006). Portanto, o social e o individual estão totalmente imbricados e, para compreender as práticas sociais em uma determinada situação de comunicação, é imprescindível tomar em conta as dimensões sociais, cognitivas e linguísticas (SCHNEUWLY; DOLZ, 2004).

Assim, o existir

se cumpre realmente e irremediavelmente através de mim e dos outros - e, certamente, também no ato de minha ação-conhecimento; ele é vivenciado, asseverado de modo emotivo-volitivo, e o conhecer não é senão um momento deste vivenciar-asseverar global. A singularidade única não pode ser pensada, mas vivida de modo participativo. (BAKHTIN, 2010, p.58)

Essa vivência social linguageira ${ }^{2}$ materializa-se em enunciados, que refletem as condições específicas e as finalidades de cada campo por seu conteúdo (temático), estilo da linguagem e, especialmente, por sua construção composicional, ou seja, os gêneros textuais (BAKHTIN, 2010, p.262).

\footnotetext{
${ }^{2} \mathrm{O}$ termo linguageiro tem sido usado por tradutores dos textos do Grupo de Genebra, em uma tentativa de expressar a referência que o termo francês langagière faz tanto a restrições estritamente linguísticas quanto a restrições situacionais, interativas e discursivas.
} 
Um contexto colaborativo e reflexivo tem potencial para desencadear significações, revolução e evolução, sendo as duas últimas "tomadas como formas de desenvolvimento mutuamente relacionadas" (BAKHTIN, 2007, p.8183).

Com o intuito de prover subsídios para o estabelecimento de um ambiente propício ao desenvolvimento, a unidade foi construída a partir da consideração de que conhecer a história de uma ciência e contar a própria história é um exercício de autoconsciência, de distanciamento que faz com que o narrador, numa espécie de reflexão interna, seja espectador de si mesmo, ou seja, um eu que deseja contar sua história pessoal, que cria e ao mesmo tempo observa, dialoga e intervém no processo de criação (VASCONCELOS; CARDOSO, 2009).

Nessa perspectiva, o contar histórias não é somente um processo de coleta e organização de dados, mas uma fase de questionamentos e autoconhecimento, em que a linguagem usada para narrar momentos passados proporciona reflexão, partilha, discussão e construção de significados para essas experiências, o que torna o processo colaborativo.

Quanto ao gênero documentário, presente na unidade, Nichols (2005, p.26) defende que todo filme é um documentário, porque evidencia "a cultura que a produziu e reproduz a aparência das pessoas que fazem parte dela". Por essa razão, o autor afirma que há dois tipos de filme, cujas histórias, ou narrativas, são de naturezas diferentes: a) documentário de satisfação de desejos e 2) documentários de representação social, caso do documentário empregado.

A tradição dos documentários de representação social, normalmente chamados de não-ficção, "está profundamente enraizada na capacidade de ele nos transmitir uma impressão de autenticidade [...] (NICHOLS, 2005, p. 20)" ao passo que "representam de forma tangível aspectos de um mundo que já ocupamos e compartilhamos (NICHOLS, 2005, p. 26)." Dois dos objetivos dos produtores são exercer um impacto no mundo histórico e atrair nossa atenção para mundos que, de outra forma, não nos atrairiam. Ao fazer isso, podem 
transmitir significados, valores, verdades, que precisam ser avaliadas pelos telespectadores.

Como o documentário, outro gênero abordado, biografia, tem um papel histórico e social crucial, porque faculta a reflexão "não somente sobre a coletividade humana e o processo evolutivo da história, mas a própria relação indivíduo x mundo" (CARINO, 2004, apud ALONSO; CRISTOVÃO, 2007, p. 180). Biografias são definidas por Costa como

Narração oral, escrita ou visual dos fatos particulares das várias fases da vida de uma pessoa ou personagem (gênero literário ou não) em livro, filme, texto teatral, disco óptico, etc. Quanto à forma, pode ser elaborada em ordem cronológica ou em forma narrativa (COSTA, 2008, p.42).

Alonso e Cristovão (2007) analisaram um conjunto de biografias e concluíram que, geralmente, as biografias constituem-se como narrativas, havendo uma relação de autonomia do agente produtor com relação ao texto. Para isso, as unidades dêiticas (pronomes) não remetem a um produtor empírico, mas sim externo ao texto. O tempo verbal predominante é, comumente, o pretérito, causando o mesmo efeito de distanciamento (ALONSO; CRISTOVÃO, 2007)

Com relação aos mecanismos de textualização das biografias, as pesquisadoras (ALONSO; CRISTOVÃO, 2007) apontam que os advérbios e locuções adverbiais são frequentemente empregados para expressar valores temporais (cronológicos) e espaciais (lugares). As anáforas pronominais de retomada também são recorrentes para dar continuidade aos fatos, ao retomar o nome do biografado, por exemplo. Por fim, as autoras defendem que o trabalho com esse gênero facilita a conscientização dos papéis assumidos entre os interlocutores, sua função social, causas, consequências, ideologias etc.

Já autobiografia é definida por Silva e Cristovão (prelo) como um gênero textual em que o agente produtor retrata a história da própria vida.

[...] ao produzir um texto autobiográfico o agente produtor não faz um simples exercício de relatar algo, mas, ao falar de si, precisa distanciar-se para desenvolver a história do "eu" e, ao mesmo tempo, conhecer a própria história. Desse modo, a tematização da autobiografia dá-se na história de vida do agente 
produtor, cujo objetivo é apresentar um relato com fatos mais marcantes de sua vida. (SILVA; CRISTOVÃO, prelo).

Desse modo, é a biografia em primeira pessoa, um gênero textual predominantemente da ordem do narrar, um relato. Segundo as estudiosas (SILVA; CRISTOVÃO, prelo), o texto pode estar em diferentes formas: histórias de vida, memória, narrativa autobiográfica, relato autobiográfico, depoimento, etc.

Por meio da análise de duas autobiografias, Silva e Cristovão (2011) apontam que geralmente os textos têm caráter subjetivo, da ordem do narrar, que se caracteriza por sua subjetividade na apresentação de fatos marcantes da vida do agente produtor. Para isso, o tempo verbal predominante é o pretérito do indicativo. Elementos coesivos temporais são frequentes assim como as modalizações apreciativas sobre os fatos narrados e o uso exagerado de adjetivos.

O trabalho com gêneros textuais na sala de aula pode contribuir para o desenvolvimento de capacidades de linguagem, isto é, conhecimentos de certo gênero textual necessários para agir em determinada situação de comunicação (DOLZ; PASQUIER; BRONCKART, 1993). Didaticamente, são divididas em capacidade de ação, referentes ao contexto; capacidade discursiva, relacionadas à organização do texto e ao posicionamento do produtor; capacidade linguístico-discursiva, referente aos usos das estruturas da língua; capacidade de significação, referente à construção de sentido mediante representações e/ou conhecimentos sobre práticas sociais (CRISTOVÃO; STUTZ, 2011). Vale lembrar que as capacidades estão completamente imbricadas e foram divididas pelos pesquisadores apenas com fins didáticos.

\section{Descrição do percurso}

A unidade foi realizada com estudantes de quinto período dos cursos de Biotecnologia, Farmácia e Química. O estabelecimento de ensino, uma instituição federal do Rio de Janeiro, é reconhecido pela comunidade por sua relevância na formação de técnicos em áreas específicas. Os alunos têm em 
média 16-18 anos e as turmas de língua inglesa são divididas em dois grupos com uma média de 15 alunos cada, sendo um de alunos que se consideram iniciantes e outro de estudantes que avaliam serem intermediários e avançados com relação à língua. No curso de Biotecnologia, as aulas são semanais, de oitenta minutos cada. Já nos cursos de Farmácia e Química, há duas aulas semanais, de oitenta minutos. A disciplina é obrigatória, entretanto, os alunos têm autonomia para optar por frequentar ou não as aulas já que a reprovação ocorre pela média de faltas no curso e não em disciplinas isoladas.

A unidade do conteúdo programática em foco é denominada $A$ História da Química, que tem por objetivo trabalhar algumas estratégias de leitura e contribuir para que o aluno conheça a história da ciência com a qual pretende trabalhar e também amplie vocabulário específico.

Como já apontado, alguns gêneros textuais foram empregados, sendo eles: o documentário Chemistry - a volatile history ${ }^{3}$; biografias de estudiosos famosos; entrevista; narrativas de vida. Tendo em vista que este texto tem a intenção de descrever o trabal ho realizado e apontar contribuições plausíveis, as atividades foram analisadas e os propósitos do uso de cada gênero selecionado foram investigados assim como os tipos de atividade realizadas, as capacidades de linguagem que puderam se desenvolver a partir do que foi feito. Dessa forma, foi viável notar a interligação entre as intenções e o que foi realizado para que fosse possível perceber se os objetivos traçados poderiam ser alcançados e de que maneira.

Com relação ao documentário, o vídeo foi visto em sala de aula e os alunos fizeram anotações para que, em seguida, pudessem completar um resumo que englobava as descobertas, local onde aconteceram, datas e cientistas. Em sequência, foi feita uma discussão sobre a história narrada e a

\footnotetext{
3 Produzido em língua inglesa pela BBC e lançado em 2010, Chemistry - a volatile history conta a história da química, em três episódios de aproximadamente sessenta minutos, narrados por Jim Al-Khalili. O documentário é do gênero história da ciência e foi indicado, em 2010, ao Prêmio de Televisão Britânica British Academy Television Awards.
} 
maneira como isso foi feito. Neste momento, houve espaço para um debate sobre impressões pessoais e informações conhecidas/novas, relevantes/dispensáveis, etc., e como todas elas foram organizadas e apresentadas. Além disso, houve uma breve discussão sobre o gênero documentário e suas características, envolvendo o contexto, a organização e a estrutura da língua.

O próximo gênero usado foi biografias de estudiosos que contribuíram para o desenvolvimento da área da química. Seu estudo foi realizado a partir de textos levados pelos participantes, que inicialmente foram convidados a ler o texto rapidamente e elaborar um resumo, ou seja, a apreensão do conteúdo temático.

O segundo passo foi a leitura mais detalhada do texto em busca de informações específicas da vida dos biografados, tais como nome completo, data de nascimento e morte, local de nascimento, local de trabalho, descoberta(s). A realização dessa leitura teve o intuito de contribuir para que o estudante compreendesse detalhes do texto, da vida do biografado e os organizasse de forma sucinta. A partir dessa leitura, os estudantes foram orientados a selecionar algumas informações e criar uma atividade de verdadeiro ou falso para que os colegas pudessem realizar. A finalidade de tal atividade era levar os alunos a analisar mais profundamente os textos $\mathrm{e}$ conscientizar-se do processo de seleção de informações, além de possibilitar uma leitura rápida de vários textos.

$O$ trabalho com narrativas de vida intencionou colaborar para que 0 aprendiz se distanciasse de sua própria vida para compreendê-la e narrá-la e, assim, se desenvolvesse não apenas como profissional. Esse desenvolvimento pode ser coletivo, a partir do momento que as histórias são compartilhadas.

Dadas as semelhanças entre os gêneros biografia e autobiografia, ambos foram explorados concomitantemente, para que os aprendizes pudessem estudar as características dos gêneros, contrastá-los, avaliar seus próprios textos e fazer alterações se necessário. Assim, após a realização das atividades de verdadeiro ou falso já mencionadas, os estudantes foram convidados a produzir a primeira versão de suas narrativas, em sala de aula. 
Feita a primeira versão, as biografias foram retomadas para o estudo de elementos organizacionais e linguístico-discursivos. As características de um texto narrativo foram discutidas do mesmo modo que sua organização em forma de tópicos ou temas, como eram construídos alguns dos textos lidos. Também foram abordados o tempo verbal predominante (pretérito do indicativo), usado para conferir distanciamento aos fatos narrados; elementos coesivos temporais, usados para organizar o texto cronologicamente; e ainda o uso de adjetivos e modalizações apreciativas, conferindo subjetividade ao texto.

Ao final dessa etapa, os participantes fizeram apresentações de suas narrativas por meio de vídeos; narração oral; narração oral com fotos ou objetos, tais como brinquedos e instrumentos musicais.

Devido ao envolvimento dos estudantes, decidimos coletivamente pela continuidade do trabalho. Na nova fase, as vidas de outros membros da comunidade escolar (professores e funcionário) foram levadas para a sala de aula. Para isso, optamos por realizar entrevistas com algumas pessoas selecionadas por cada dupla e a apresentação livre novamente, ou seja, por meio de vídeo ou apresentação oral, contando com a presença de todos os alunos e ainda de alguns professores.

\section{Ponderações sobre a experiência}

O quadro a seguir resume o trabalho realizado, exibindo os objetivos, as atividades $e$ as capacidades de linguagem que presumivelmente foram mobilizadas.

\begin{tabular}{|c|l|l|l|}
\hline Gênero & \multicolumn{1}{|c|}{ Objetivos } & \multicolumn{1}{|c|}{ Atividades } & \multicolumn{1}{c|}{$\begin{array}{c}\text { Capacidades de } \\
\text { linguagem } \\
\text { mobilizadas }\end{array}$} \\
\hline Documentário & $\begin{array}{l}\text { Introduzir o tema da } \\
\text { unidade; } \\
\begin{array}{l}\text { Alimentar reflexões sobre } \\
\text { a história da química; } \\
\text { Suscitar discussões sobre } \\
\text { a forma como a história } \\
\text { foi retratada no }\end{array}\end{array}$ & $\begin{array}{l}\text { Assistir o vídeo, tomada } \\
\text { de notas de pontos } \\
\text { considerados relevantes; } \\
\text { Resumo do vídeo; } \\
\text { Discussão oral }\end{array}$ & $\begin{array}{l}\text { Capacidades de } \\
\text { ação, discursiva, } \\
\text { linguístico-discursiva } \\
\text { e de significação }\end{array}$ \\
\hline
\end{tabular}




\begin{tabular}{|c|l|l|l|}
\hline $\begin{array}{c}\text { Biografias de } \\
\text { estudiosos }\end{array}$ & $\begin{array}{l}\text { documentário } \\
\text { estudiosos da área; } \\
\text { Refletir sobre a } \\
\text { construção da história }\end{array}$ & $\begin{array}{l}\text { Leitura rápida, detalhada } \\
\text { e de busca de } \\
\text { informações específicas; } \\
\text { Discussão oral }\end{array}$ & $\begin{array}{l}\text { Capacidades de } \\
\text { ação, discursiva, } \\
\text { linguístico-discursiva } \\
\text { e de significação }\end{array}$ \\
\hline $\begin{array}{c}\text { Narrativas de } \\
\text { vida }\end{array}$ & $\begin{array}{l}\text { Ponderar sobre o curso } \\
\text { da própria vida; } \\
\text { Tomar consciência de } \\
\text { eventos vividos e da } \\
\text { constituição de sua } \\
\text { individualidade. }\end{array}$ & $\begin{array}{l}\text { Produção e apresentação } \\
\text { da narrativa }\end{array}$ & $\begin{array}{l}\text { Capacidades de } \\
\text { ação; discursiva; } \\
\text { linguístico-discursiva } \\
\text { e de significação }\end{array}$ \\
\hline $\begin{array}{c}\text { Vídeos e } \\
\text { entrevistas }\end{array}$ & $\begin{array}{l}\text { Conhecer um pouco } \\
\text { sobre a vida das pessoas constituem a } \\
\text { que çituão }\end{array}$ & $\begin{array}{l}\text { Discussão e produção de } \\
\text { questões para } \\
\text { entrevistas; } \\
\text { Entrevista com } \\
\text { professores e } \\
\text { funcionários; } \\
\text { Elaboração e } \\
\text { apresentação de vídeos } \\
\text { sobre a vida dos } \\
\text { entrevistados. } \\
\text { Organização de DVD }\end{array}$ & $\begin{array}{l}\text { Capacidades de } \\
\text { ação, discursiva, } \\
\text { linguístico-discursiva } \\
\text { e de significação. }\end{array}$ \\
\hline
\end{tabular}

Quadro 1: Resumo dos gêneros abordados, objetivos, atividades e possibilidades de desenvolvimento de capacidades de linguagem

Chemistry - a volatile history relata como os elementos químicos foram descobertos e mapeados. De acordo com a BBC, produtora do documentário, o físico teórico Jim Al-Khalili seguiu os passos dos pioneiros para compreender como uma nova ciência foi criada, nos levando à era moderna.

A introdução da unidade por meio desse documentário de representação social (NICHOLS, 2005) teve a intenção de alimentar reflexões sobre a história da química (ordem das descobertas, a (não) relevância das descobertas, a (não) valorização de descobertas) e ainda alimentar discussões sobre a forma como a história foi retratada no documentário (autenticidade, relevância de cada descoberta, etc.). Com a discussão, as quatro capacidades de linguagem foram mobilizadas e possivelmente desenvolvidas, com ênfase maior nas capacidades de ação e de significação.

No caso da capacidade de ação, houve espaço para a compreensão do contexto tanto da história da química quanto do documentário - suas intenções; o papel social dos envolvidos - emissora, diretor, apresentador, telespectadores. Quanto à capacidade discursiva, ao resumir o documentário e discuti-lo, os estudantes tiveram a oportunidade de organizar os fatos e 
perceber sua seleção e ordenação. Também foi debatida a proximidade do narrador com o telespectador e com a situação. Em termos de capacidade linguístico-discursiva, a linguagem adotada foi discutida (formal/informal) bem como a proximidade ou distanciamento do interlocutor por meio do uso de dêiticos ou de frases não-declarativas (interrogativas, afirmativas e negativas) e as intenções. Com relação à capacidade de significação, houve espaço para reflexões sobre os propósitos do documentário, razões pelas quais ele é organizado de determinada maneira, traz determinadas informações e omite outras, é apresentado por um físico, etc.

Da mesma maneira que o documentário, o próximo gênero abordado, biografia, tem um papel histórico e social crucial, como assevera Carino (apud ALONSO; CRISTOVÃO, 2007, p. 180).

As leituras e as atividades propostas constituíram-se como oportunidades de ampliação de conhecimento sobre descobertas da área e descobridores, da mesma forma que as reflexões sobre a construção da história e da subjetividade de sua interpretação. Isso pode ser feito com discussões sobre as escolhas das informações presentes no texto, por exemplo, e da ênfase dada a determinados aspectos, omissão de outros, etc.

Tratando-se da capacidade discursiva, seu desenvolvimento foi oportunizado com a elaboração de resumos dos textos, a observação da organização dos mesmos e da linguagem usada. Este último item está em relação direta com o aumento da capacidade linguístico-discursiva, propiciada pela discussão e sistematização de alguns elementos recorrentes no gênero, tais como o tempo verbal mais comum (pretérito perfeito) e advérbios de tempo para organizar cronologicamente o que está sendo narrado. Com relação à capacidade de significação, foram suscitadas reflexões sobre o papel social de biógrafos e biografados; ponderações sobre a construção social da história e das diferentes possibilidades de interpretação a depender de questões subjetivas, tais como background do produtor do texto e intenções, em contraste com a linguagem empregada e a organização dos textos.

Como já mencionado, os alunos foram convidados a trazer para a sala de aula a biografia de um pesquisador selecionado por eles como relevante para a 
área. Ao longo da aula, os textos foram lidos individualmente, de maneira guiada. Tendo a maioria dos textos sido retirada da Wikipedia, o início das discussões se configurou como um espaço de reflexão e contraste entre as características, os usos, a confiabilidade, credibilidade de tal enciclopédia em português e em inglês, embora esse não tenha sido um objetivo planejado.

Após a discussão inicial, as biografias foram lidas, primeiramente, de forma superficial, e, em seguida, detalhada em busca de informações específicas, tais como nome completo, data de nascimento e morte, local de nascimento, local de trabalho, descoberta(s). A produção de uma atividade com base na leitura feita contribuiu para que os alunos se conscientizassem da organização dos textos, das informações contidas e de sua relevância, e ainda de como selecionar informações para resumir um texto.

Considerando que construímos nossa identidade com base em nossas experiências e também em exemplos, a leitura das biografias pode ter contribuído para que os alunos se situassem em contraste com outros e, a partir desse processo, tomassem consciência de quem são, do caminho que têm trilhado e podem trilhar, etc., valorizassem a história da área de investigação, de pesquisadores/profissionais e de si, além de refletir sobre perspectivas futuras.

Conjuntamente ao estudo de biografias e de forma processual, foram desenvolvidas narrativas de vida, com o intuito de incentivar a reflexão sobre o curso da própria vida e a tomada de consciência de eventos vividos e da constituição de sua individualidade. Desse modo, houve a primeira produção, realizada em sala; a revisão em pares e pelo professor; a reescrita e a versão final, que se materializou de formas diversas: relato falado; álbum de fotos com explicações; exposição de objetos com explicações; vídeos com imagens, fotos, músicas, etc.

Vale mencionar que o envolvimento dos participantes na construção de suas próprias histórias foi gradual, na medida em que foram descobrindo momentos não reconhecíveis, como apontam Vasconcelos e Cardoso (2009). Para exemplificar, quando a atividade foi proposta, uma aluna disse que não conseguiria fazer porque sua vida tinha apenas dezesseis anos e não tinha 
nenhum acontecimento que merecesse ser compartilhado já que se resumia à vida cotidiana, escolar e familiar. $\mathrm{Na}$ aula seguinte, a estudante entrou em sala entusiasmada, com sua narrativa praticamente pronta, dizendo que, ao chegar em casa, conversou com seu pai sobre o tema e percebeu que tinha muito para compartilhar. Outro exemplo é de um aluno que não conhecia nenhum membro de sua família, além dos pais. Ele demonstrou resistência para realizar o trabalho, argumentando ser a história desnecessária e inútil. Aos poucos, foi mudando de postura e, ao final do processo, quis entrevistar um professor, uma faxineira e uma secretária.

A produção de narrativas pode ter contribuído para o aumento das quatro capacidades de linguagem, na medida que permitiu a reflexão sobre o contexto e a compreensão da organização de textos dessa natureza, a liberdade de expressão, tanto em termos de conteúdo, quanto de organização ou linguagem utilizada, como apontam Silva e Cristovão (prelo). Além disso, houve espaço para reflexões sobre os acontecimentos vividos, suas relações com sua personalidade, suas atitudes, suas conquistas e fracassos, etc.; também houve a possibilidade de aprofundamento de conhecimentos sobre a vida dos colegas em contraste com a sua e a de outros colegas e uma esperada maior compreensão das atitudes de outros colegas e uma aproximação entre eles.

Ainda é justificável apontar que a produção e o compartilhamento de narrativas constituiram-se como espaços de distanciamento da própria vida para compreendê-la e narrá-la e, assim, de desenvolvimento não apenas como profissional. O desenvolvimento pode ser coletivo, a partir do momento em que as histórias são compartilhadas. O tipo de apresentação variou de narração oral a scrapbooks, apresentações em slides e vídeos. No geral, a organização dos textos foi cronológica ou temática (às vezes, apenas um ou dois temas, especialmente amigos; outras vezes, vários, incluindo geralmente infância, família, escola, amigos, viagens).

É aceitável dizer que esse foi um momento importante de nossa disciplina e do curso, pois constituiu-se como um espaço de compartilhamento 
e construção coletiva, gerando reflexões, emoções, dúvidas, e, consequente, desenvolvimento.

Como já mencionado, optamos coletivamente pela continuidade do trabalho. Na nova fase, as vidas de outros membros da comunidade escolar (professores e funcionário) foram trazidas para a sala de aula. Para isso, em duplas, os participantes investigaram a vida de um membro da comunidade escolar (professor ou funcionário). Para a geração de dados, foram realizadas entrevistas, que serviram de embasamento para a produção biográfica a ser compartilhada com os colegas, em forma de vídeo ou apresentação oral com exposição de fotos ou qualquer outro documento, objeto, etc.

A preparação para as entrevistas aconteceu em sala de aula, momento em que foi oportuno discutir questões relacionadas ao gênero entrevista, tais como influência dos papeis sociais dos envolvidos e especialmente do tipo de pergunta. Vale mencionar que, embora a preparação tenha sido feita para realizar as entrevistas em língua inglesa, todas acabaram sendo feitas em português, por opção dos participantes, ou por falta de conhecimento da língua ou por conforto.

A produção de tais apresentações teve 0 intento de proporcionar 0 conhecimento sobre a vida e os estudos de pessoas que constituem a instituição. Foram feitas discussões tanto sobre o processo de elaboração das entrevistas quanto na fase de produção das apresentações e ao longo das exposições. A comunidade escolar envolveu-se e participou ativamente. Assim, as atividades realizadas constituíram-se como um espaço de partilha, de conscientização, de compreensão de si e do outro, ou seja, um espaço de desenvolvimento coletivo.

\section{Considerações finais}

O trabalho no ensino-médio técnico profissionalizante pressupõe a contribuição para o desenvolvimento profissional e a formação cidadã dos estudantes. Nesse ambiente, a atividade coletiva e cooperativa é 
extremamente benéfica, porque viabiliza a construção de conhecimento e propicia o desenvolvimento.

Conhecer a história da ciência em estudo, dos professores e construir e compartilhar narrativas de vida, tendo um público real que vai além dos colegas de turma, no caso, professores e funcionários da escola, pode se constituir como um espaço privilegiado de desenvolvimento pessoal e profissional, individual e coletivo, que é justamente a principal finalidade de uma sala de aula de línguas.

Reichman (2010), por exemplo, afirma que a reconstrução de sua história de vida e experiências educacionais por meio de memórias a tornou mais consciente de sua posição enquanto profissional e a fez aprender para a vida toda. A pesquisadora também aponta que ao textualizar sua prática, ela teve uma melhor percepção de suas origens, ampliando seus horizontes profissionais e percebendo que tinha algo criativo a dizer.

À medida que todos os alunos foram tendo a mesma consciência, passaram a colaborar uns com os outros, trocar experiências e assim, certamente, cresceram enquanto grupo e indivíduo. Também tiveram a oportunidade de perceber a distinção entre escrever como possibilidade de transcrever palavras e escrever como direito de transcrever sentidos (VASCONCELOS; CARDOSO, 2009).

Tanto o exemplo de Reichman (2010) quanto dos dois alunos mencionados na parte anterior confirmam que a circunstância de conhecer a história, no caso a da química, e construir e compartilhar a própria narrativa e as histórias de vida de outros participantes da mesma comunidade, permite que os participantes dividam suas experiências de vida com o grupo, o que os ajuda a construir significados em uma perspectiva colaborativa e propulsora de desenvolvimento em termos vigotskianos, já que contribui para a imersão em sua própria vida e, ao mesmo tempo, o distanciamento para ser capaz de buscar sentido para eventos relatados.

Trabalhos como esse em sala de aula de língua estrangeira permitem que o aluno perceba a língua como ação social (BAZERMAN, 2005) e desenvolva capacidades de linguagem, se interesse por aprendê-la e ainda desenvolva-se 
profissionalmente e como indivíduo, valorizando a história e tornando-se consciente de contextos micro e macro que envolvem sua vida e sua área de atuação.

\section{Referências bibliográficas}

ALONSO, T.; CRISTOVÃO, V. L. L. Biografias em inglês: uma abordagem do gênero sob a visão sócio-interacionista. In: CRISTOVÃO, V. L. L. Modelos didáticos de gêneros: uma abordagem para 0 ensino de língua estrangeira. Londrina: UEL, 2007.

BAKHTIN, M. M. Para uma filosofia do ato responsável. Trad. Valdemir Miotello e Carlos Alberto Faraco. São Carlos: Pedro \& João Editores, 2010. p.41-144.

BAKHTIN, M. M. Estética da criação verbal. Trad. Paulo Bezerra. $5^{a}$. Ed. São Paulo: Editora WMF Martins Fontes, 2010.

BAZERMAN, C. Gêneros textuais, tipificação e interação. Organização de Dionisio, A. P.; Hoffnagel, J. C. e tradução e adaptação de Judith Chambilis Hoffnagel. São Paulo: Cortez Editora, 2005.

BEATO-CANATO, A. P. M. O trabalho com línguas para fins específicos em uma perspectiva interacionista sociodiscursiva. RBLA, Belo Horizonte, v. 11, n. 4, p.853-870, 2011.

BRASIL. Documento Base da Educação Profissional Técnica de Nível Médio Integrada ao Ensino Médio. Brasília: Secretaria de Educação Profissional e Tecnológica, 2007.

BRONCKART, J-P. Atividade de linguagem, discurso e desenvolvimento humano. Org. Anna Rachel Machado e Maria de Lourdes Meirelles Matencio. Trad. Anna Rachel Machado, Maria de Lourdes Meirelles Matencio [et. al]. Campinas: Mercado de Letras, 2006.

COSTA, S. R. Dicionário de gêneros textuais. Belo Horizonte: Autêntica Editora, 2008.

CRISTOVÃO, V. L. L.; STUTZ, L. Sequências didáticas: semelhanças e especificidades no contexto francófono como $L 1$ e no contexto brasileiro como LE. In: SZUNDY, P. T. C.; ARAÚJO, J. C.; NICOLAIDES, C. S.; SILVA, K. A. (org.) Linguística Aplicada e Sociedade - Ensino e aprendizagem de línguas no contexto brasileiro. Campinas (SP): Pontes Editores, 2011, p. 1739. 
DOLZ, J.; PASQUIER, A.; BRONCKART, J-P. L'acquisition des discours: emergence d'une compétence ou apprentissage de capacités langagières? Études de Linguistique Appliquée, 102, p.23-37, 1993. p.23-37.

RAMOS, R. C. G. Gêneros textuais: uma proposta de aplicação em cursos de inglês para fins específicos. The ESPecialist, v. 25, n. 2, p. 107-129, 2004.

NICHOLS, B. Introdução ao documentário. Trad. Mônica Saddy Martins. Campinas (SP): Papirus, 2005.

REICHMAN, C. L. Constructing communities of practice through memoirs and journals. In: BURTON, J.; QUIRKE, P.; REICHMAN, C. L.; PEYTON, J. K. (ed.) Reflective writing: a way of lifelong teacher learning. 2nd. Ed. United States: TESL-EJ Publications, 2010. p.49-62.

VASCONCELOS, S. M. F.; CARDOSO, M. N. F. Novas Fronteiras Lingüísticas: um estudo sobre o gênero autobiográfico. Revista Eutomia, ano II - n 01 (652-664), 2009.

VIGOTSKI, L. S. A formação social da mente: o desenvolvimento dos processos psicológicos superiores. Trad. José Cipolla Neto; Luís Silveira Menna Barreto, Solange Castro Afeche. $7^{\mathrm{a}}$. Ed. São Paulo: Martins Fontes, 2007.

SCHNEUWLY, B.; DOLZ, J. Os gêneros escolares - das práticas de linguagem aos objetos de ensino. In: SCHNEUWLY, B.; DOLZ, J. et al. Gêneros orais e escritos na escola. Trad. e org. Roxane Rojo e Glaís Sales Cordeiro. Campinas: Mercado de Letras, 2004. p.71-91.

SILVA, A. P. da; CRISTOVÃO, V. L. L. Modelo didático do gênero autobiografia: desenvolvimento na formação em pré-serviço. prelo. 
Artigo recebido em: 10/12/2013

Artigo avaliado em: 26/05/2014

Sobre a autora:

Professora do Programa Interdisicplinar de Pós-Graduação em Linguística Aplicada e Professora de Língua Inglesa do Departamento de AngloGermânicas da Universidade Federal do Rio de Janeiro. 